\title{
Cartografia do patrimônio geomorfológico voltada à interpretação geoturística
}

\author{
The geomorphological heritage cartography focused on the \\ geotouristic interpretation
}

\author{
Adriano Severo Figueiró, Universidade Federal de Santa Maria, Brasil, adriano.figueiro@ufsm.com.br \\ (1) https://orcid.org/0000-0002-4988-771X \\ Maurício Mendes Von Ahn, Universidade Federal de Pelotas, Brasil, mauricio.von.ahn@gmail.com \\ (D) http://orcid.org/0000-0001-8442-2056
}

\begin{abstract}
Resumo: Este trabalho tem como objetivo colaborar com as discussões que envolvem a representação cartográfica dos elementos associados ao patrimônio geomorfológico, a fim de investigar como vem ocorrendo no Brasil a comunicação do conteúdo geocientífico com o público não especialista. Para atender ao objetivo utilizou-se a classificação de mapas geoturísticos para não especialistas proposta por Géraldine Bissing, da universidade de Lausanne. Foram selecionados 27 mapas geoturísticos oriundos de pesquisas brasileiras, onde buscou-se enquadrá-los dentro da classificação de mapas geoturísticos. Identificou-se que $85 \%$ dos mapas elaborados no Brasil são de pequena escala, apresentando uma falta de informações científicas e turísticas. Em relação à simbologia, apenas $11 \%$ dos mapas utilizam símbolos figurativos, os quais são os mais adequados para fins geoturísticos, uma vez que a informação não foi apenas simplificada, mas sim traduzida para uma linguagem facilmente compreensível pelo público não especialista. No caso dos mapas elaborados no Brasil, constatou-se o uso de fotografias de campo no entorno do layout de alguns mapas a fim de tornar mais efetiva a comunicação do conteúdo com o público não especialista. Conclui-se que se faz necessária uma cartografia própria à interpretação geoturística, baseada em representações e interesses de grupos e indivíduos, a fim de compreender a sua efetividade na difusão do conhecimento sobre o patrimônio geomorfológico com o público não especialista.
\end{abstract}

Palavras-chave: Patrimônio geomorfológico; Geoconservação; Geoturismo; Interpretação ambiental; Cartografia geomorfológica.

\begin{abstract}
This work is aimed to collaborate with the discussions that involve the cartographic representation of the elements associated to the geomorphological heritage, in order to investigate how the communication of geoscientific content is being made in Brazil with the non-specialist group. In order to suit the purpose, we used the classification of geotouristic maps for non-specialists proposed by Géraldine Bissing from the University of Lausanne. 27 geotouristic maps from Brazilian researches were selected, where we sought to suit them into the classification of geotouristic maps. It has been identified that $85 \%$ of the maps elaborated in Brazil are small scale, presenting a lack of scientific and touristic information. Concerning symbolism, only $11 \%$ use figurative symbols which are more adequate for geotouristic purposes as the information was not only simplified but also adapted for an easily understandable language for the non-specialist public. In the case of maps elaborated in Brazil, it was found the use of field pictures around the layout of some maps in order to make the content communication more effective with the non-specialist public. We conclude that it is necessary to develop a cartography proper for the geotouristic interpretation, based on representations and interests of groups and individuals in order to understand its effectiveness for the diffusion of knowledge about the geomorphological heritage with the non-specialist public.
\end{abstract}

Keywords: Geomorphological heritage; Geoconservation; Geotourism; Environmental interpretation; Geomorphological cartography. 


\section{Introdução}

No que se refere às pesquisas realizadas no campo de identificação, classificação e avaliação de geossítios e geomorfossítios, os métodos de representação cartográfica destes espaços ainda são pouco explorados, pese embora a sua grande relevância para o suporte da atividade geoturística. Tal fato é assumido na atualidade como um problema para quem trabalha com as temáticas correlatas à geoconservação (Carton et al., 2005; Reynard et al., 2007), já que a cartografia do território representa um elemento central do processo de comunicação, sendo, portanto, ferramenta estratégica da geoconservação (Figura 1).

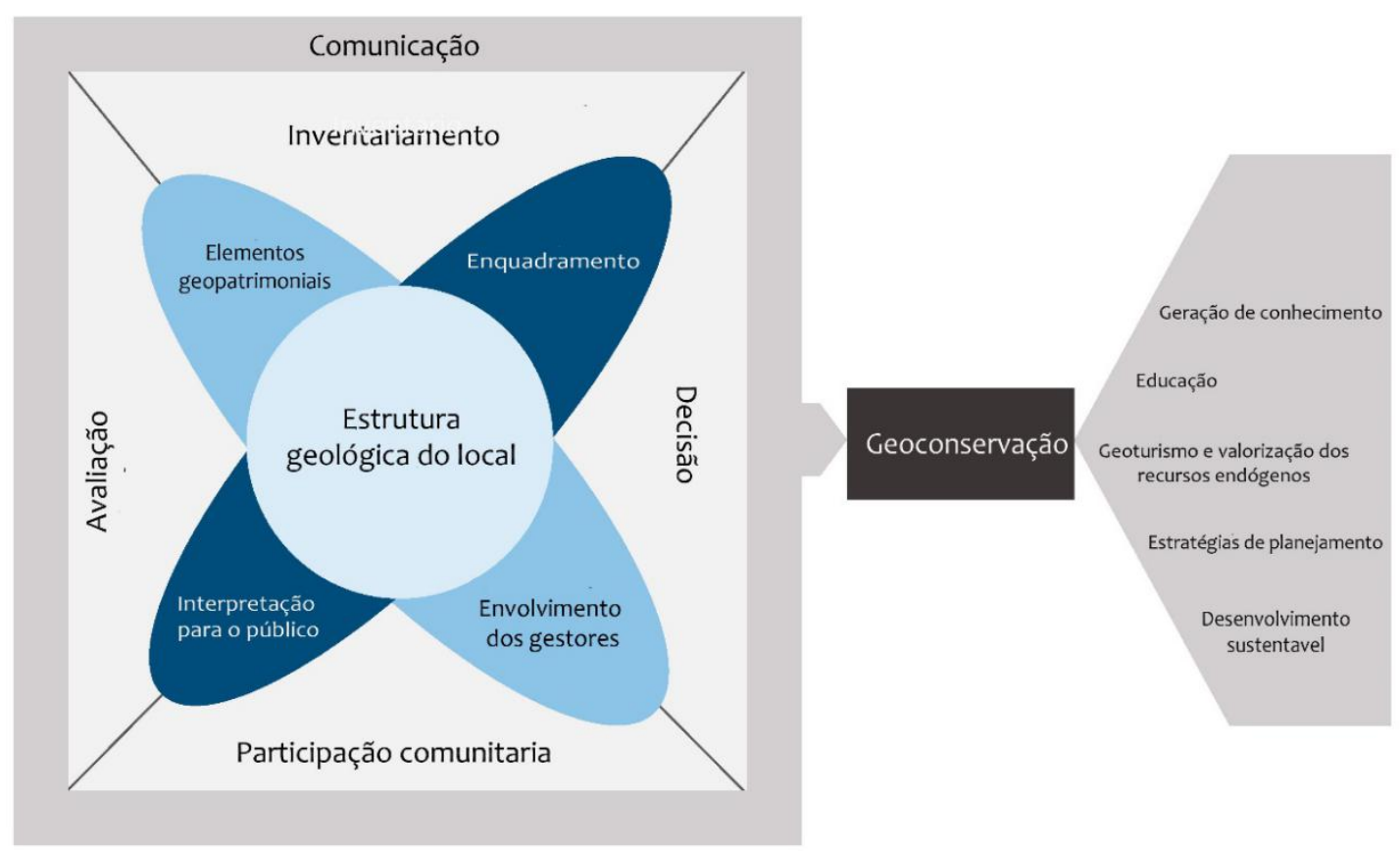

Figura 1: Esquema das diferentes fases do processo de avaliação geopatrimonial, com destaque para a comunicação como ferramenta estratégica da geoconservação.

Fonte: Adaptado de Tavares et al. (2015).

Carton et al. (2005) propuseram a distinção entre duas categorias de mapas, dependendo do usuário: mapas para especialistas e mapas para não especialistas. De acordo com esses autores, o primeiro grupo pode ser muito útil no planejamento e gestão territorial (por exemplo, para avaliação de impacto ambiental), e na sua elaboração são utilizados símbolos geomorfológicos tradicionais que mostram o conjunto de formas do relevo que compõem um geomorfossítio, enquanto que todos os outros elementos da paisagem são omitidos. O segundo grupo refere-se a mapas produzidos, sobretudo, para a comunicação do conteúdo científico com o público não especialista (Carton et al., 2005).

Estudos pioneiros atentaram para a representação cartográfica de geomorfossítios a partir da elaboração de mapas geomorfológicos (Zouros, 2005), mapas de geomorfossítios (Pereira, 2006; Reynard et al., 2007), mapas de patrimônio 
geomorfológico (Cunha, Vieira, 2004; Pereira, 2006) e mapas geoturísticos (Lambiel, Reynard, 2003).

Contudo, Regolini (2012) destaca que com a finalidade de proporcionar um maior entendimento do público não especialista, em muitos casos na elaboração dos mapas ocorre uma redução do número de formas geomorfológicas e uma simplificação da legenda geomorfológica tradicional (por exemplo, com a adoção de um único símbolo para deslizamentos de terra ativos e inativos). Para a autora citada o que está faltando muitas vezes é uma verdadeira abordagem da mediação científica, que inclui o estabelecimento de diretrizes e princípios de trabalho para o desenvolvimento de mapas efetivamente voltados para não especialistas.

Segundo El Hadj (1985),

Para estar bem informado, é necessário que o pesquisador possa ouvir e identificar as representações, e os interesses do público-alvo. Um conhecimento genuíno de grupos e indivíduos permitirá uma comunicação atraente e estimulante, capaz de suscitar interesse, atrair atenção e pensar (El Hadj, 1985, p. 78).

Portanto, a transição da representação técnica para representações comunicativas, e vice-versa, está na essência do problema de pesquisa, pois se observa a ausência de uma cartografia própria que, por meio da seleção de conteúdo e símbolos, possa ser compreendida pelo público não especialista, uma vez que mapas geomorfológicos tradicionais requerem habilidades de leitura específicas. Esta é uma questão crucial quando se pretende aproximar a representação do relevo (principal técnica de trabalho da geomorfologia) da representação do patrimônio geomorfológico e da cartografia de geomorfossítios.

Buscando atender às diferentes lacunas identificadas, este trabalho tem como objetivo colaborar com as discussões que envolvem a representação cartográfica dos elementos associados ao patrimônio geomorfológico, a fim de investigar e discutir como vem ocorrendo no Brasil a comunicação do conteúdo geocientífico com o público não especialista que visita locais de valor geopatrimonial.

\section{Metodologia}

Para o desenvolvimento desta pesquisa foram analisados conceitos e obras que possibilitaram colaborar com as discussões envolvendo representação cartográfica e os elementos associados à geodiversidade e ao patrimônio geomorfológico. Considerações sobre como vem ocorrendo a comunicação do conteúdo geocientífico com o público não especialista também foram feitas, principalmente a partir da análise de alguns métodos de representação cartográfica de geomorfossítios e mapas geoturísticos publicados.

Ao final, foi realizada uma investigação sobre como vem ocorrendo no Brasil a comunicação do conteúdo geocientífico com o público não especialista. Para isso, utilizou-se a classificação e análise de mapas geoturísticos para não especialistas proposta por Géraldine Bissig, da universidade de Lausanne, que analisou 51 mapas 
de oito países europeus e os classificou em cinco diferentes grupos. Com base nesta classificação, foram selecionados 27 mapas geoturísticos oriundos de pesquisas brasileiras, os quais foram enquadrados dentro da proposta de Bissig (2008), a fim de identificar de que forma vem ocorrendo a difusão do conhecimento geocientífico em território nacional.

A seleção das referências bibliográficas e, consequentemente, dos mapas geoturísticos, ocorreu em bases de dados online, tais como: bibliotecas digitais de universidades brasileiras e internacionais; Biblioteca Digital Brasileira de Teses e Dissertações (BDTD); Web of Science; Google Acadêmico; Portal de Periódicos CAPES/MEC; e Scientific Eletronic Library Online (SCIELO). O período de busca e revisão destas obras ocorreu entre Maio e Julho de 2019.

\section{Cartografia do patrimônio geomorfológico: a interpretação por parte do público não especialista}

Diante da fragilidade dos recursos naturais e a degradação diretamente associada às necessidades de produção e consumo humano, faz-se necessário buscar o equilíbrio ambiental e promover o desenvolvimento sustentável, de forma a proteger esses recursos e garantir também a qualidade de vida (Brilha, 2005). Portanto, visando evitar uma maior degradação ambiental da Terra e diante da necessidade emergente de conservação e valorização dos componentes da geodiversidade, desenvolveram-se na última década os estudos vinculados à geoconservação (Sharples, 2002; Kozlowski, 2004; Brilha, 2005).

A geodiversidade abrange o conjunto de recursos geológicos, geomorfológicos, seus fenômenos e processos ativos, bem como outros sistemas criados como resultados dos processos naturais endógenos e exógenos e a atividade humana, que dão origem às paisagens terrestres (Nieto, 2001; Prosser, 2002; Gray, 2004; Kozlowski, 2004). Esse fato demonstra a representatividade que a geodiversidade possui no cenário de conservação da natureza, sendo considerada como o suporte para a sustentação dos ecossistemas e da biodiversidade, devendo ser considerada para fins de gestão, tomada de decisão, planejamento e educação (Gray, 2004; Brilha, 2005; Gordon, 2012).

A geoconservação abrange o conjunto de estratégias para a proteção da geodiversidade (Sharples, 2002; Brilha, 2005), tendo como objetivo preservar as ocorrências geológico-geomorfológicas resultantes de processos naturais e/ou antrópicos, que possuam inegável valor científico, pedagógico, cultural ou turístico: os geossítios (Brilha, 2005). O conjunto dos geossítios de determinado território contém o seu geopatrimônio, que abrange, entre outros, as formas do relevo e seus depósitos correlatos, os quais isoladamente ou em conjunto possuem significância para determinados processos morfogenéticos de uma dada região (Vieira, Cunha, 2004; Brilha, 2005).

O conceito de geodiversidade possui suas raízes no patrimônio geológico (Johansson et al., 1999; Nieto, 2001; Stanley, 2001), embora as abordagens que consideram os 
elementos geomorfológicos no estudo da geodiversidade sejam, ainda, recentes (Reynard et al., 2007; Prieto, 2013; Pereira et al., 2013a; Pereira et al., 2013b; Silva et al., 2015; Reynard et al., 2016).

Pereira (2006) considera que os geossítios nos quais as formas do relevo são o seu elemento mais valioso devem ser designados de locais de interesse geomorfológico. Já Reynard (2003) e Gentizon (2003) referem-se à expressão paisagem geomorfológica e consideram que a proteção destas estruturas permite a conservação da própria dinâmica natural que, afinal, é responsável pela sustentação de certos biótopos.

Pereira (1995) define o patrimônio geomorfológico como o conjunto de formas do relevo e depósitos correlativos que apresentam claro interesse científico devido às suas características genéticas e de conservação, pela sua raridade e/ou originalidade, pelo seu grau de vulnerabilidade, ou ainda, pela maneira como se combinam espacialmente. Com base nestas considerações realizadas por Pereira (1995), Reynard (2003) diferencia os geossítios de base geológica dos geomorfossítios, com caráter geomorfológico, que corresponde ao conjunto de formas do relevo com valor científico, histórico, material, não-material, cultural, estético e socioeconômico (Reynard, 2003; Reynard, Panizza, 2005; Panizza, Piacente, 2008).

A interpretação da geodiversidade é a base para uma estratégia de geoturismo (Rodrigues, Carvalho, 2009; Moreira, 2009), considerado um dos mais novos segmentos de turismo, onde as pessoas que realizam este tipo de atividade possuem interesse pelos aspectos geológicos e geomorfológicos de um determinado território (Moreira, 2009). As ocorrências de cunho geomorfológico por si só passam despercebidas aos olhos dos visitantes, sendo necessário preparar o território com ferramentas que possibilitem um maior entendimento científico dos pontos de interesse geomorfológico.

Carton et al. (2005) propõem diretrizes para a elaboração de mapas geomorfológicos de geomorfossítios. Os autores apontam que a cartografia de geomorfossítios deve permitir uma percepção imediata da distribuição das formas do relevo no território, tanto pelo pessoal técnico quanto pela população em geral, o que é fundamental para o ordenamento do território, sendo um meio efetivo para a comunicação e difusão do conhecimento.

Um impulso considerável para as investigações sobre este tema foi dado por trabalhos de vários autores, especialmente na Europa (Carton et al., 2005; Castaldini et al., 2005; Bissig, 2008; Coratza, Regolini-Bissig, 2009; Regolini, 2012), os quais ilustram alguns métodos para a representação cartográfica de geomorfossítios.

Coratza e Regolini-Bissig (2009) utilizam-se do conceito de codificação e decodificação do mapa geomorfológico, onde a codificação diz respeito à elaboração do mapa, e a decodificação corresponde à interpretação do mapa pelo usuário. Segundo Regolini (2012), em muitos casos as escolhas relativas ao público-alvo, o conteúdo científico e a forma de representação cartográfica desta informação são, de 
fato, pouco ou nada explícitas. Esta falta de informação sobre a fase de codificação ocorre, segundo a autora, devido à ausência de uma abordagem metodológica claramente definida, o que leva à reflexão superficial no momento de elaboração dos mapas.

Segundo Bissig (2008), dentro dos estudos associados ao geoturismo, o mapa pode intervir em dois níveis diferentes: como ferramenta de trabalho e como ferramenta de comunicação.

Como ferramenta de trabalho, para gerentes de um geoparque, por exemplo, o mapa pode servir para ilustrar distância de um local a outro, ou mesmo para expor locais suscetíveis a algum tipo de risco natural. O mapa, portanto, auxiliaria no monitoramento de um geossítio ou geomorfossítio.

Como ferramenta de comunicação, o mapa é uma aplicação para o público em geral. A função principal de um mapa, neste caso, é servir como um dispositivo de orientação, podendo ser utilizado como um método de visualização de informações geocientíficas (Bissig, 2008; Coratza, Regolini-Bissig, 2009). Essa função é muito importante, pois alguns processos que contribuíram para a formação de um geomorfossítio ou de uma paisagem geomorfológica nem sempre são visíveis na paisagem.

A fim de identificar como os geomorfossítios estavam sendo representados, bem como para realizar um debate acerca da importância da informação científica e turística nos mapas, Bissig (2008) realizou um estudo com base na produção de mapas geoturísticos na Europa. A autora analisou 51 mapas geoturísticos levando em consideração fatores como escala (pequena e grande), simbologia (símbolos pontuais, símbolos de mapeamento geomorfológico clássico e símbolos figurativos) e quantidade de informações adicionais (poucas ou muitas informações). As características dos cinco diferentes tipos de mapas definidos pela autora podem ser observadas na Tabela 1.

A análise da autora com base nos mapas europeus mostrou que o potencial de comunicação dos mapas é atualmente subdesenvolvido, uma vez que apenas $16 \%$ dos mapas analisados são considerados os mais eficientes (Tipo 5). Segundo Bissig (2008), a produção de mapas geoturísticos é realizada de acordo com princípios pouco claros e parece ser guiada mais por preocupações estéticas do que por preocupações didáticas.

As informações levantadas por Bissig (2008) foram confrontadas com mapas geoturísticos elaborados no Brasil, a fim de identificar de que forma vem ocorrendo a difusão do conhecimento geocientífico em território nacional. 
Tabela I: Representação esquemática das principais características dos diferentes tipos de mapas.

\begin{tabular}{|c|c|}
\hline Tipo de mapa & Características \\
\hline Tipo 1: Mapas gerais & $\begin{array}{l}\text { São caracterizados por uma representação esquemática (por exemplo, das formas de } \\
\text { relevo) e são de pequena escala (> 1:25.000). Os geomorfossítios são marcados com } \\
\text { símbolos pontuais indicando sua localização. Este tipo de representação cartográfica } \\
\text { possui uma falta de informações adicionais que não permite ao usuário apreciar } \\
\text { imediatamente o conteúdo, fazendo com que a informação científica e turística seja } \\
\text { insuficiente. }\end{array}$ \\
\hline Tipo 2: Mapas geoturísticos & $\begin{array}{l}\text { Em comparação com os mapas gerais, os mapas geoturísticos fornecem mais } \\
\text { informações turísticas, como áreas de estacionamento, espaços para piquenique, } \\
\text { hotéis e pousadas, etc. Devido à pequena escala destes mapas ( } 1: 25.000 \text { ) } \\
\text { frequentemente topográficos ou esquemáticos, os geomorfossítios são sempre } \\
\text { representados por símbolos pontuais. A informação científica é insuficiente mesmo } \\
\text { que a informação turística seja satisfatória. }\end{array}$ \\
\hline $\begin{array}{c}\text { Tipos } 3 \text { e } 4 \text { : Mapas } \\
\text { geocientíficos para amadores } \\
\text { da ciência da Terra }\end{array}$ & $\begin{array}{l}\text { O termo foi escolhido para designar os mapas de escalas pequenas ( }>1: 25.000) \text { a } \\
\text { grandes ( }<1: 25.000 \text { ), que incluem um importante componente geológico e/ou } \\
\text { geomorfológico. A distinção entre os tipos } 3 \text { e } 4 \text { é necessária devido à representação } \\
\text { dos próprios geomorfossítios, representados como símbolos pontuais no primeiro } \\
\text { caso (Tipo 3) ou por símbolos de mapeamento tradicional no segundo caso (Tipo 4). } \\
\text { Consequentemente, o conteúdo científico dos mapas é alto para os dois tipos. O } \\
\text { conteúdo turístico varia entre médio (tipo } 3 \text { ) e alto (tipo 4). }\end{array}$ \\
\hline Tipo 5: Mapas interpretativos & $\begin{array}{l}\text { O nome se baseia no caráter "interpretativo" desses mapas. Um conjunto de } \\
\text { símbolos ou símbolos figurativos são projetados em um fundo esquemático de } \\
\text { grande escala }(<1: 25.000) \text {. Isso permite que as formas do relevo sejam mostradas. } \\
\text { Este tipo de mapa oferece uma mescla de informações sobre as ciências da Terra e } \\
\text { as informações turísticas. }\end{array}$ \\
\hline
\end{tabular}

\section{Mapas geoturísticos no Brasil: análises e perspectivas}

\section{Os 27 mapas geoturísticos oriundos de pesquisas brasileiras foram enquadrados dentro da classificação de Bissig (2008) obtendo-se o resultado apresentado no Gráfico 1.}

Gráfico 1: Classificação dos mapas geoturísticos brasileiros analisados nesta pesquisa.

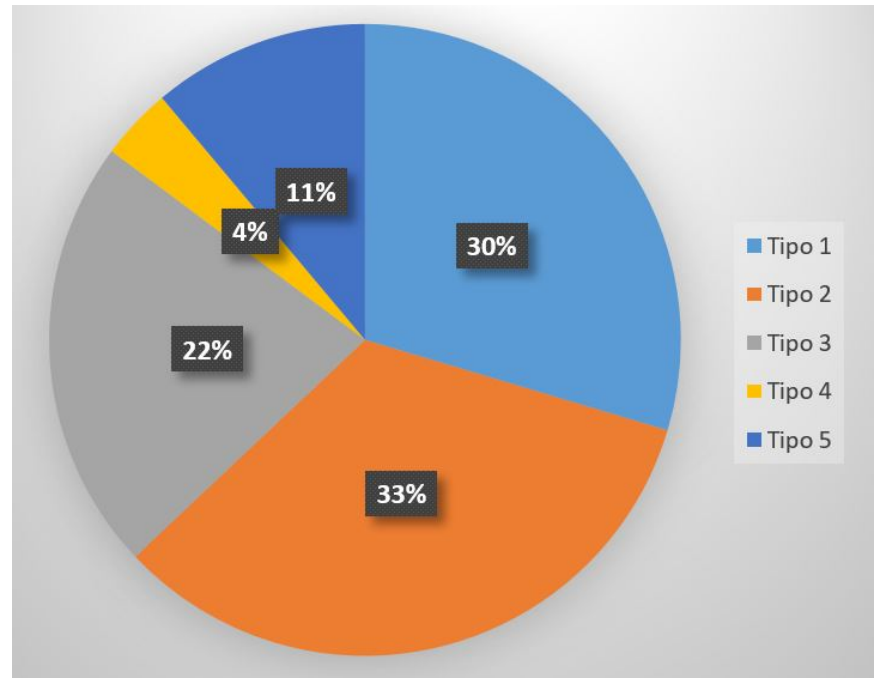


Os mapas do Tipo 1 e Tipo 2 são fontes de informação bastante precárias. Estes mapas auxiliariam, por exemplo, no planejamento de uma viagem, particularmente na seleção de locais a serem visitados, para os quais as informações turísticas básicas estão disponíveis. Por outro lado, tais mapas não fornecem nenhuma informação científica imediata, a qual deve ser obtida a partir de outros meios de comunicação que acompanham o mapa. As Figuras 2 e 3 consistem em exemplos de mapas gerais (Tipo 1) e mapas geoturísticos (Tipo 2).

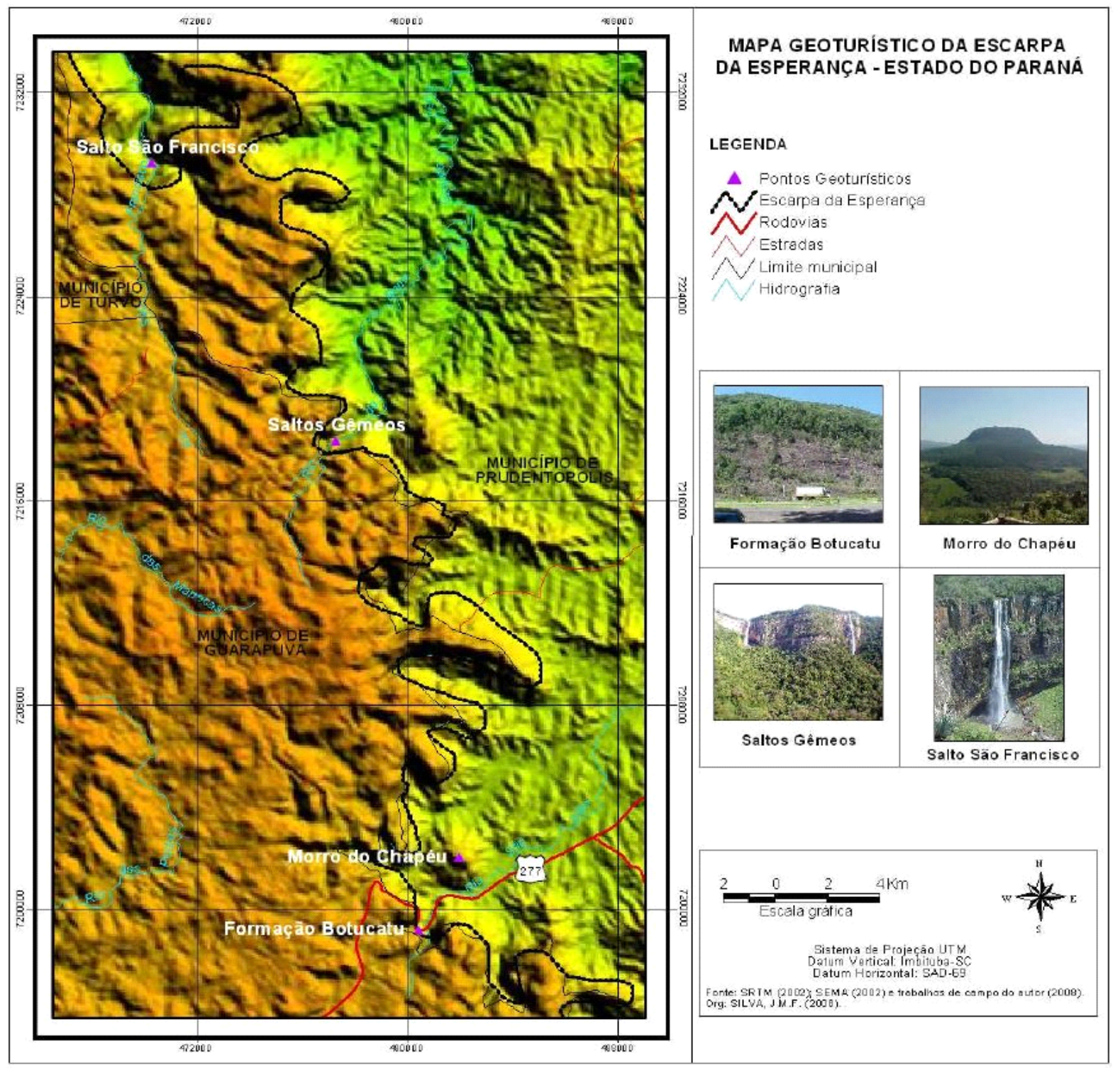

Figura 2: Mapa classificado como de "tipo 1" da Escarpa da Esperança - PR, como exemplo de mapa geral.

Fonte: Silva e Oka-Fiori (2002). 


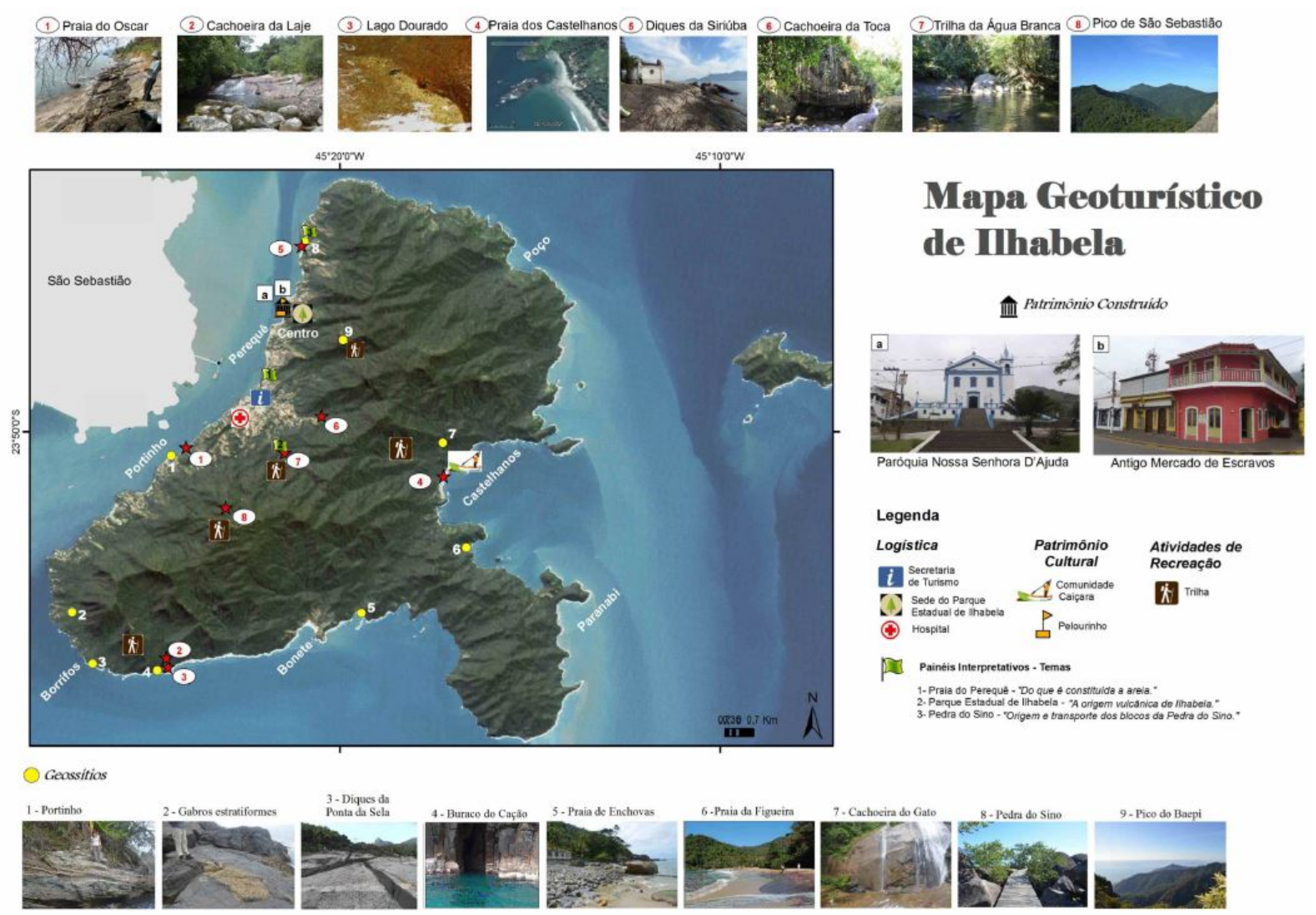

Figura 3: Mapa classificado como de "tipo 2" de llhabela - SP, como exemplo de mapa geoturístico. Fonte: Arruda (2017).

Os mapas do Tipo 3 e Tipo 4 tem como objetivo a comunicação do conteúdo científico com o público em geral. Para Bissig (2008), apesar de uma suposta simplificação do mapa original, as legendas ainda são complexas e, portanto, um conhecimento geocientífico se faz necessário para usar efetivamente esse tipo de mapa. Para a autora, o usuário pode ficar desanimado e pode preferir mudar diretamente para o texto e as ilustrações exibidas nas margens ou no verso do mapa. Esses mapas serviriam mais como uma fonte de informações turísticas sobre a região (Figuras $4 \mathrm{e}$ 5).

Para Bissig (2008), no caso dos mapas interpretativos (Tipo 5), o ponto extremamente positivo diz respeito a escala, que faz com que o território representado apresente um menor nível de generalização, o que permite que as formas de relevo sejam claramente exibidas. Os símbolos figurativos usados para designar as formas do relevo específicas mostram claramente onde o usuário precisa focar a atenção. 


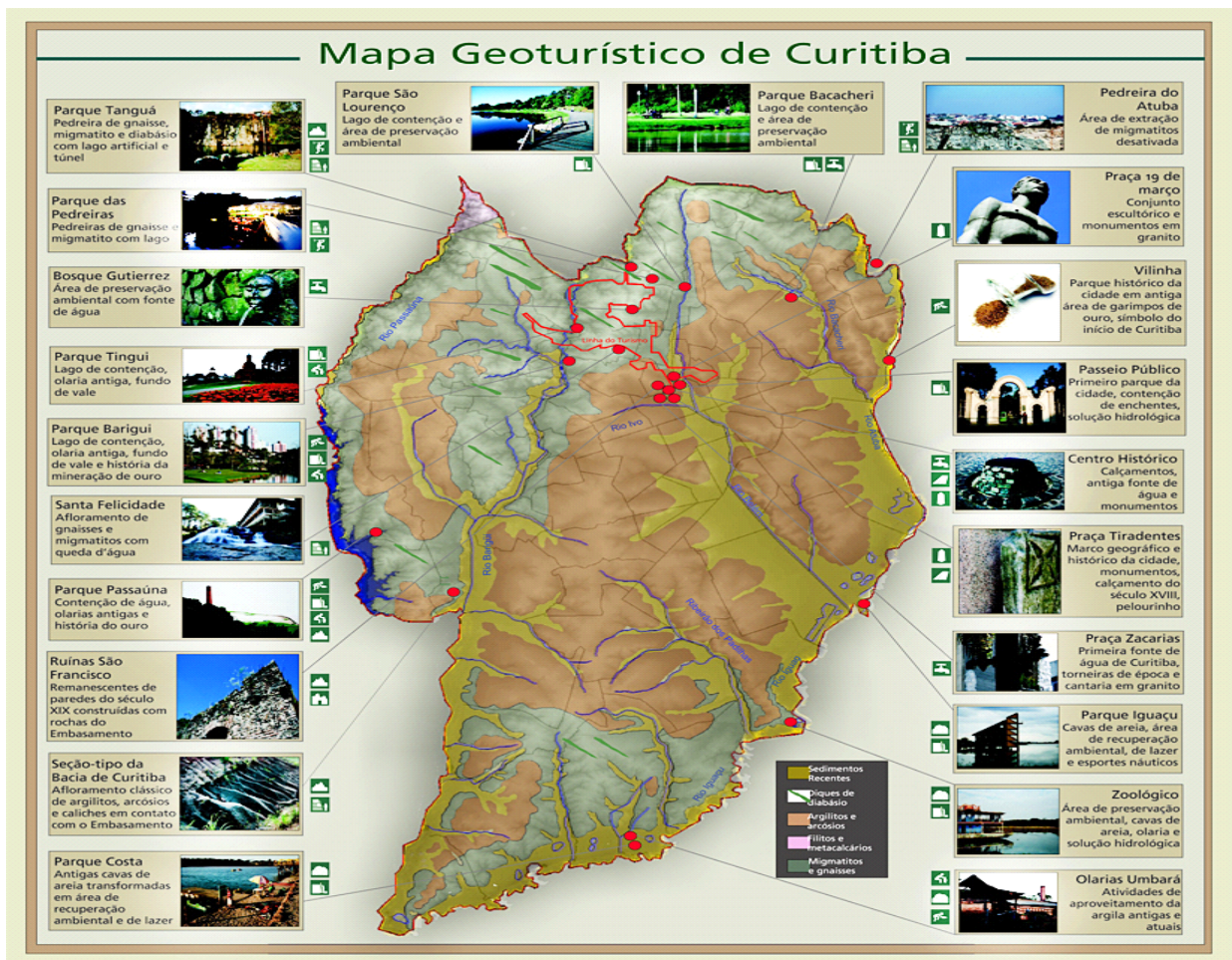

Figura 4: Mapa classificado como de "tipo 3" de Curitiba - PR como exemplo de mapa geocientífico para amadores da ciência da Terra.

Fonte: Liccardo et al. (2008).
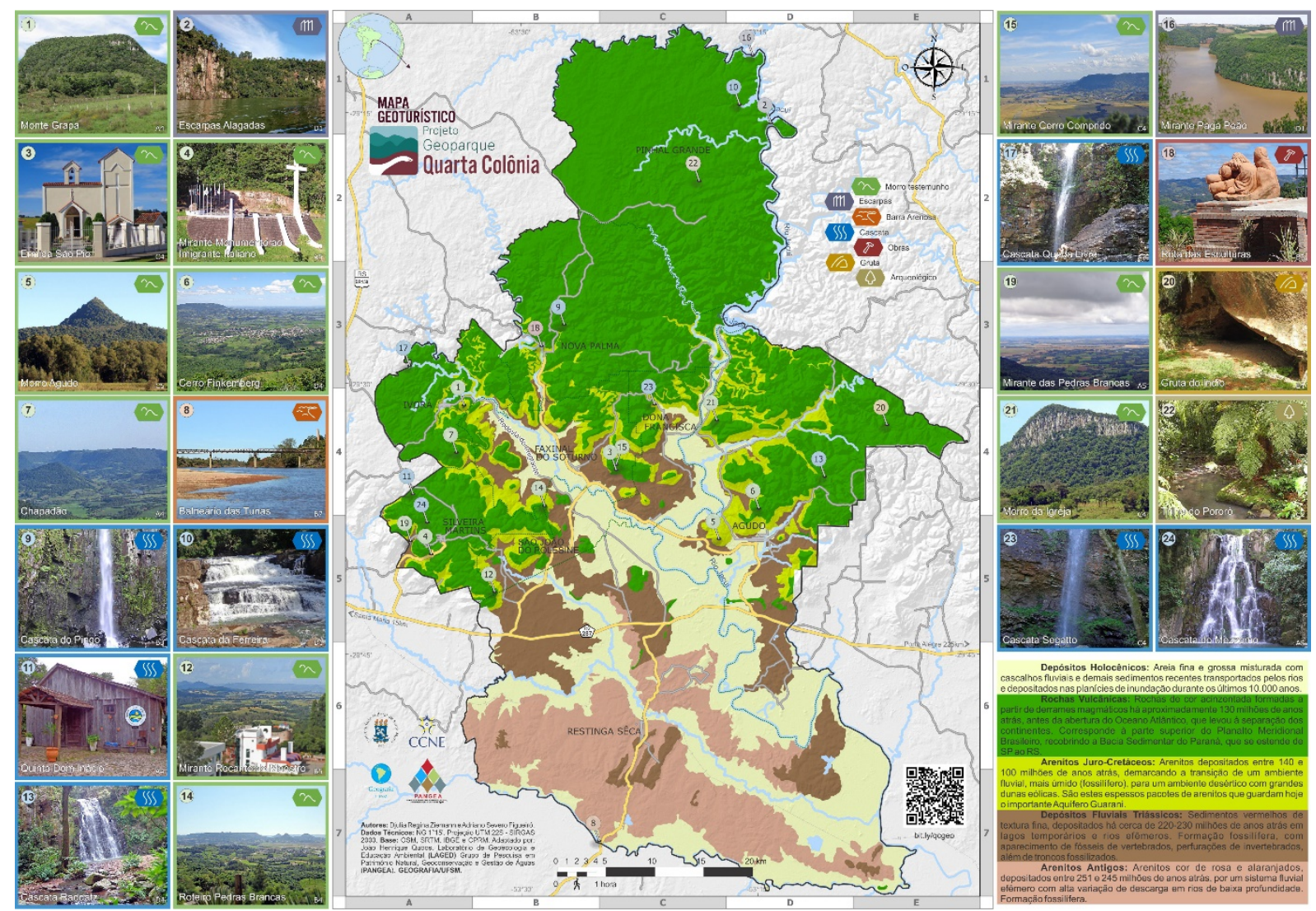

Figura 5: Mapa classificado como de "tipo 4" do território do Geoparque Quarta Colônia (RS) como exemplo de mapa geocientífico para amadores da ciência da Terra (Tipo 4).

Fonte: Cechin (2019). 
Neste caso, a informação principal não foi apenas simplificada, mas também traduzida para uma linguagem facilmente compreensível para o público não especialista. Os elementos turísticos também são destacados com o duplo objetivo de fornecer informações sobre atividades complementares e facilitar a orientação. Isso resulta em mapas facilmente legíveis e comunicáveis com o público não especialista (Figura 6).

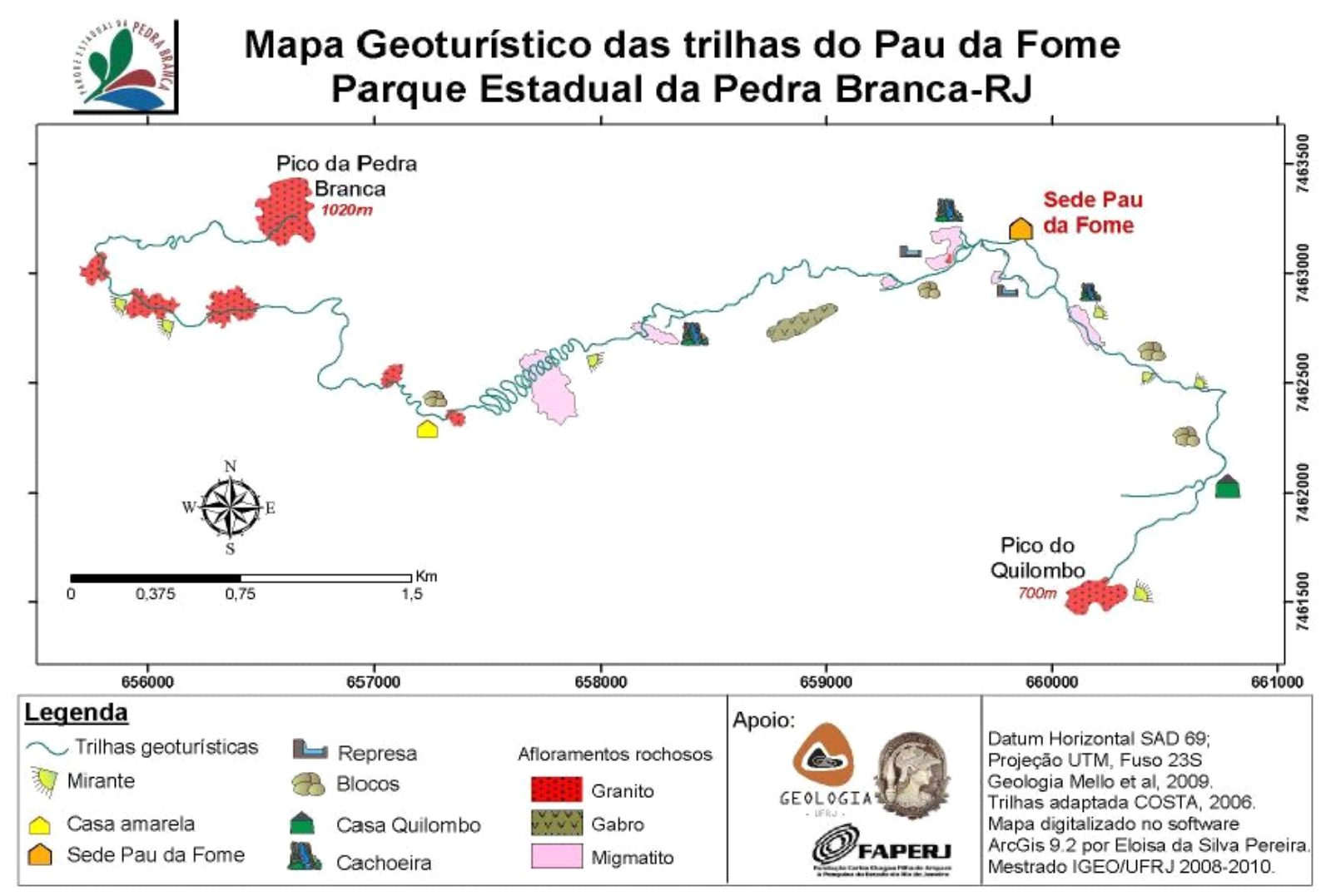

Figura 6: Mapa classificado como de "tipo 5" das trilhas do Pau da Fome - RJ, como exemplo de mapa interpretativo.

Fonte: Pereira (2010).

Por fim, a partir do levantamento realizado, identificou-se que $85 \%$ dos mapas geoturísticos analisados são de pequena escala (Tipos 1, 2 e 3). Estes mapas não permitem informações de detalhe, uma vez que a realidade acaba sendo muito reduzida. Portanto, apresentam uma falta de informações, o que não permite ao usuário apreciar imediatamente o conteúdo, onde tanto a informação científica quanto a informação turística acaba sendo insuficiente.

Em relação a simbologia, os mesmos $85 \%$ dos mapas são marcados por símbolos pontuais, indicando a localização das informações, e apenas $4 \%$ utilizam símbolos geológicos e geomorfológicos tradicionais, o que é um ponto positivo, pois a leitura efetiva desta simbologia técnica se torna complexa para o público não especialista. Os demais $11 \%$ utilizam símbolos figurativos, os quais são os mais adequados para fins geoturísticos, uma vez que a informação não foi apenas simplificada, mas sim 
traduzida para uma linguagem facilmente compreensível pelo público não especialista.

\section{Conclusões}

Conclui-se que se faz necessária uma cartografia geomorfológica própria à interpretação geoturística, baseada em representações e interesses de grupos e indivíduos, a fim de compreender a sua efetividade na comunicação e difusão do conhecimento sobre o patrimônio geomorfológico com o público não especialista. A sua ausência pode ser explicada pelo fato das pesquisas nesse âmbito serem extremamente recentes, bem como pela ausência de padrões internacionais de mapeamento geomorfológico.

No caso dos mapas elaborados no Brasil, constatou-se uma particularidade, onde 15 dos 27 mapas analisados fazem uso de fotografias de campo no entorno dos mapas, algo que em geral não ocorre nos mapas europeus. Acredita-se que essa seja uma forma que os pesquisares brasileiros tenham encontrado para tornar mais efetiva a comunicação do conteúdo com o público não especialista, podendo residir aí o início de uma metodologia nacional de compreensão e representação das paisagens de interesse geomorfológico.

Entende-se que o uso de fotografias de campo como auxílio à interpretação pode ser uma técnica efetiva; no entanto, para a melhor eficiência dos mapas, são necessários estudos para ilustrar as necessidades e os interesses do público-alvo.

Uma das questões que merecem ser melhor aprofundadas, refere-se à possibilidade de integração de materiais com diferentes escalas e formas de representação, de maneira a estabelecer diferentes níveis de informação e profundidade, inclusive com a produção de materiais de apoio que complementam e/ou melhoram a produção do mapa geoturístico impresso, como a produção de maquetes de mão por usinagem por Controle Numérico Computadorizado (CNC) ou por impressão 3D a laser. Nesta mesma linha, os mapas geoturísticos tradicionais podem ser impressos a partir de uma matriz produzida em Vacuum forming, gerando uma projeção tridimensional real ao mapa a ser interpretado (Figura 7). Esta técnica, que consiste na impressão a vácuo de mapas em folhas de plástico, passou a ser utilizada pelo serviço de cartografia do exército dos Estados Unidos após a Segunda Guerra, com a finalidade de disseminar largamente as informações do relevo com um custo consideravelmente mais baixo do que o custo de outras técnicas mais especializadas. Este processo é baseado na técnica alemã de Karl Wenschow (1884-1947), e consiste no aquecimento de uma folha termoplástica sobre um molde tridimensional previamente elaborado, seguido da aplicação do vácuo, de modo que a folha aquecida se molda perfeitamente ao modelo, e pode ser removida após alguns segundos de resfriamento. Ao longo do tempo, esta técnica foi sendo aperfeiçoada para corrigir algumas dificuldades de representação em escalas grandes; atualmente não apenas os mapas topográficos, mas também as imagens de satélite podem ser impressas em folhas de plástico. 


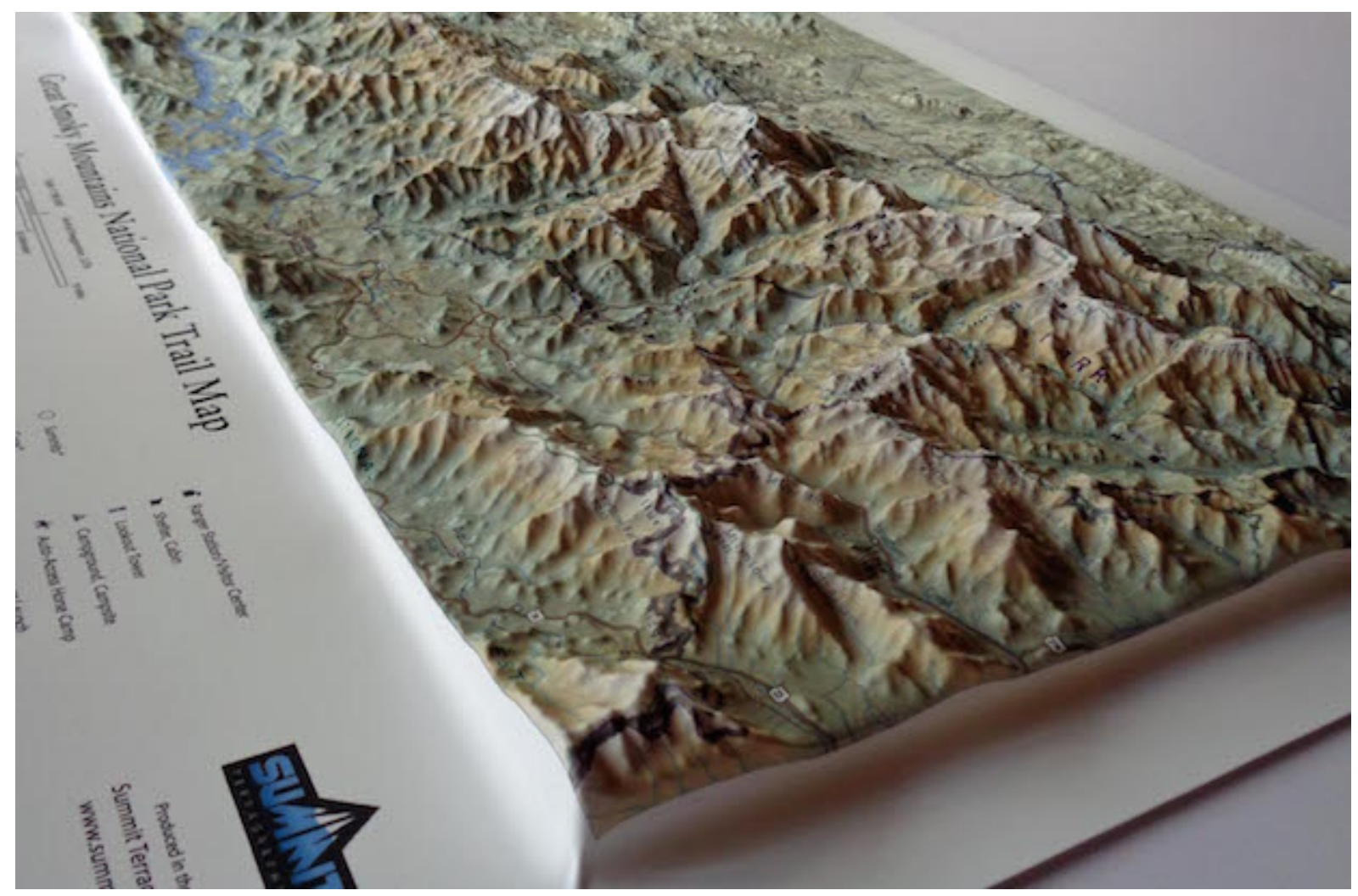

Figura 7: Mapa geoturístico do Great Smokey Mountains National Park (USA) produzido a partir de impressão em Vacuum forming.

Fonte: https://gearinstitute.com/unique-map-presents-great-smoky-mountains-in-3d/

Ao mesmo tempo, novas estratégias digitais podem ser utilizadas, prescindindo até mesmo da impressão do mapa físico, como tem sido a regra até o momento; Falamos aqui, por exemplo, da integração dos instrumentos de interpretação com as novas tecnologias, como no caso do uso da Realidade Virtual e/ou da Realidade Aumentada ${ }^{1}$ via smartphones (Figura 8). O valor principal da realidade aumentada é que ela traz componentes do mundo digital dentro da percepção da pessoa do mundo real, e não o faz apenas dispondo visualmente as informações, mas sim através da integração de sensações imersivas que são percebidas como partes naturais de um ambiente. Aqui, mais uma vez, o protagonismo coube à área militar, já que os primeiros sistemas funcionais de realidade aumentada foram testados pela força aérea americana na década de 90 . Uma vasta gama de possibilidades pode ser utilizada neste caso, desde o simples uso das câmeras de smartphones, até o uso de óculos especiais ou capacetes que aumentam ainda mais a possibilidade de imersão do visitante.

\footnotetext{
${ }^{1}$ Realidade aumentada (RA) é uma experiência interativa, onde objetos que residem no mundo real são "acentuados" por informação perceptiva criada por uma interface eletrônica, incluindo visual, auditiva, háptica, somatossensorial e/ou olfativa. Pode ser construtiva (agrega ao ambiente natural) ou destrutiva (que mascara o ambiente natural). A realidade aumentada altera o mundo real do usuário, enquanto a realidade virtual substitui completamente o mundo real do expectador.
} 


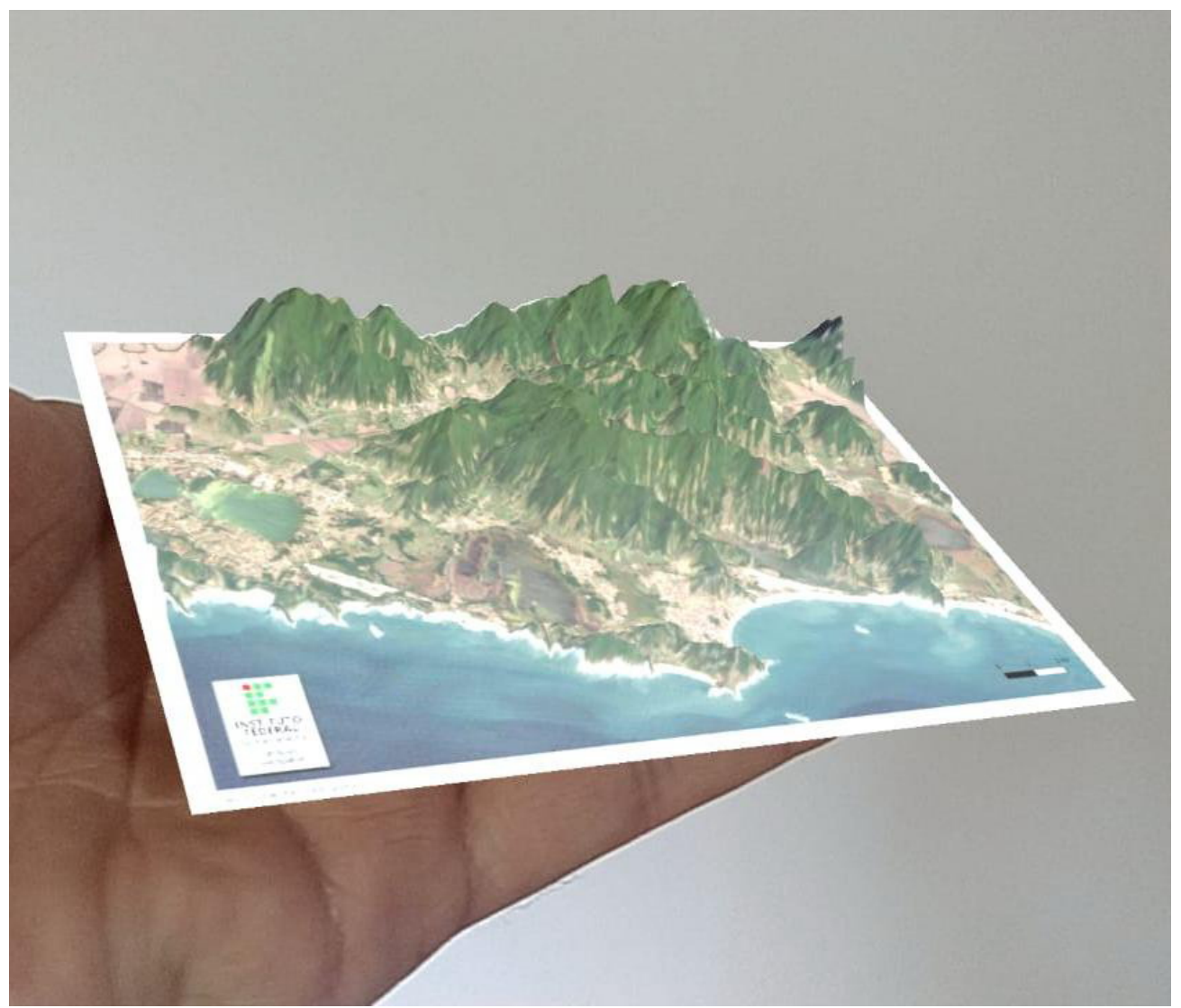

Figura 8: Mapa geoturístico da região de Garopaba (SC) produzido virtualmente em Realidade Aumentada e visualizado a partir da câmera de um smartphone.

Fonte: acervo do PANGEA

O pesquisador deve buscar esse diálogo com os visitantes, tanto especialistas como leigos, a fim de identificar os seus interesses e suas expectativas, e também analisar a maneira de assimilar as informações que lhes são oferecidas. Isso tudo pode contribuir para a elaboração de um mapa extremamente comunicativo com o público não especialista, a partir da realidade e das necessidades brasileiras.

\section{Bibliografia}

Arruda, K. E. C. (2017). A Geoconservação como subsídio à gestão territorial sustentável: o mapa geoturístico do litoral norte do estado de São Paulo. Tese de Doutorado, Universidade de São Paulo, São Paulo, Brasil.

Barreto, J. M. (2007). Patrimônio geológico e estratégias de geoconservação: popularização das geociências e desenvolvimento territorial sustentável para o litoral sul de Pernambuco (Brasil). Dissertação de Mestrado, Universidade Federal da Bahia, Salvador, Brasil.

Bissig, G. (2008). Mapping geomorphosites: an analysis of geotourist maps. Geoturystyka, 14(3), 3-12. https://doi.org/10.7494/geotour.2008.14.3

Brilha, J. (2005). Patrimônio Geológico e Geoconservação: a conservação da natureza em sua vertente Geológica. Braga: Palimage.

Carton, A., Coratza, P., Marchetti, M. (2005). Propositions pour la cartographie des sites géomorphologiques: exemples italiens. Géomorphologie: relief, processus, environnement, 11(3), 209-218. https://journals.openedition.org/geomorphologie/374 
Cecchin, D. N. (2019). Integração do patrimônio cultural ao natural como recurso geoturístico na implantação do projeto do Geoparque Quarta Colônia, RS, Brasil. Tese de Doutorado, Universidade Federal de Santa Maria, Santa Maria, Brasil.

Coratza, P., Regolini-bissig, G. (2009). Methods for mapping geomorphosites. In: E. Reynard.; P. Coratza, G. Regolini-bissig (Eds). Geomorphosites, (pp. 89- 103). München: Pfeil Verlag.

Castaldini, D., Valdati, J., Ilies, D. C. (2005). The contribution of geomorphological mapping to environmental tourism in protected areas: examples from the Apennines of Modena (Northern Italy). Revista de geomorfologie, 7, 91-106.

Cunha, L., Vieira, A. (2004). Geomorfologia, património e actividades de lazer em espaços de montanha: exemplos no Portugal Central. In: Anais do III Seminário Latino Americano de Geografia Física. México: Puerto Vallarta. http://hdl.handle.net/1822/35550

El Hadj, S. A., Bélisle C. (1985). Vulgariser: un défi ou un mythe? La communication entre spécialistes et non spécialistes. Lyon: Chronique sociale.

Gentizon, C. (2003). La géomorphologie et les paysages dans les réserves naturelles: études de cas. In: Actes du séminaire de trosième cycle de géographie, 111-121.

Gordon, J. E. (2012). Rediscovering a Sense of Wonder: Geoheritage, Geotourism and Cultural Landscape Experiences. Geoheritage, 4(1-2), 65-77. https://doi.org/10.1007/s12371-011-0051-z

Gray, M. (2004). Geodiversity: Valuing and Conserving Abiotic Nature. Chichester (U.K.): John Wiley \& Sons.

Johansson, C. E., Andersen, S. M. (1999). Geodiversity in the nordic countries. ProGeo News, 1, 1-3.

Kozłowski, S. (2004). Geodiversity: the concept and scope of geodiversity. Przegląd Geologiczny, 52(8/2), 833-837.

Lambiel, C., Reynard, E. (2003). Cartographie de la distribution du pergélisol et datation des glaciers rocheux dans la région du Mont Gelé (Valais). Phys. Geogr., 41, 91-104.

Liccardo, A., Piekarz, G. F., Salamuni, E. (2008). Geoturismo em Curitiba. Mineropar: Curitiba.

Moreira, J. C. (2009). Geoturismo: Uma Abordagem Histórico-Conceitual. In: Anais do VI Seminário da Associação Brasileira de Pesquisa e Pós-Graduação em Turismo. São Paulo: Universidade Anhembi Morumbi.

Nieto, L. M. (2001). Geodiversidad: propuesta de una definición integradora. Boletín Geológico y Minero, 112, 3-11.

Panizza, M., Piacente, S. (2008). Geomorphosites and Geotourism. Revista Geográfica Acadêmica, 2(1), 5-9.

Pereira, A. R. (1995). Património geomorfológico no litoral sudoeste de Portugal. Finisterra, XXX(59-60). https://doi.org/10.18055/Finis1813

Pereira, P. (2006). Património geomorfológico: conceptualização, avaliação e divulgação. Aplicação ao Parque Natural de Montesinho. Tese de Doutorado, Universidade do Minho, Braga, Portugal. 
Pereira, E. D. (2010). Geodiversidade do Parque Estadual da Pedra Branca-RJ: subsídios para o planejamento geoturístico. Dissertação de Mestrado, Universidade Federal do Rio de Janeiro, Rio de Janeiro, Brasil.

Pereira, E. O., Azevedo, U. R., Ondicol, R. P. (2013a). Modelagem da geodiversidade na Área de Proteção Ambiental sul da região metropolitana de Belo Horizonte - MG. Geonomos, 21(2), 97-101. https://doi.org/10.18285/geonomos.v21i2.277

Pereira, D. I., Pereira, P., Brilha, J., Santos, L. (2013b). Geodiversity Assessment of Paraná State (Brazil): an Innovative Approach. Environmental Management, 52, 541-552. https://doi.org/10.1007/s00267-013-0100-2

Prieto, J. L. P. (2013). Geositios, geomorfositios y geoparques: importancia, situación actual y perspectivas en México. Investigaciones Geográficas, Boletín del Instituto de Geografía, 82, 24-37. https://doi.org/10.14350/rig.32817

Prosser, C. (2002). Terms of endearment. Earth Heritage, 17, 12-13. Consultado em: http://www.earthheritage.org.uk/wp/wp-content/uploads/2018/03/EH17-2002.pdf

Regolini, G. (2012). Cartographier les géomorphosites. Objectifs, publics et propositions méthodologiques. These de doctorat, Université de Lausanne, Lausanne.

Reynard, E. (2003). La géomorphologie et la création des paysages. In: Actes du séminaire de trosième cycle de géographie, Paysages géomorphologiques (pp. 9-20). Lausanne: Instituts de Géographie des Universités de Lausanne et Fribourg.

Reynard, E., Panizza, M. (2005). Geomorphosites: definition, assessment and mapping. An introduction. Géomorphologie: relief, processos, environnement, 11(3), 177-180. http://journals.openedition.org/geomorphologie/337

Reynard, E., Coratza, P. (2007). Geomorphosites and geodiversity: a new domain of research. Geographica Helvetica, 62(3), 138-139.

Reynard, E., Coratza, P., Hobléa, F. (2016). Current Research on Geomorphosites. Geoheritage, 8(1). https://doi.org/10.1007/s12371-016-0174-3

Rodrigues, J., Carvalho, C. N. (2009). Geoturismo no Geopark Naturtejo - um passo na educação formal. In: Atas do XIII Encontro Nacional de Educação em Ciências.

Sharples, C. (2002). Concepts and principles of geoconservation. Tasmanian Parks and Wildlife Service.

Silva, J. M. F., Oka-fiori, C. (2002). Geomorfologia e Turismo: Potencial da Escarpa da Esperança, Centro-Sul do Estado do Paraná. In: C. Schobbenhaus (Eds) Sítios Geológicos e Paleontológicos do Brasil (pp. 501-510), 1. Ed. Brasília: DNPMCPRM.

Silva, P., Rodrigues, C., Pereira, D. I. (2015). Mapping and Analysis of Geodiversity Indices in the Xingu River Basin, Amazonia, Brazil. Geoheritage, 7, 337-350. https://doi.org/10.1007/s12371-014-0134-8

Stanley. M. (2001). Geodiversity strategy. Progeo news, 1, 6-9.

Tavares, A. O., Henriques, M. H., Domingos, A., Bala, A. (2015). Community Involvement in Geoconservation: A Conceptual Approach Based on the Geoheritage of South Angola. Sustainability, 7(5), 4893-4918. https://doi.org/10.3390/su7054893 
Vieira, A., Cunha, L. (2004). Patrimônio Geomorfológico: tentativa de sistematização. In: Actas do III Seminário Latino Americano de Geografia Física. México: Puerto Vallarta. http://hdl.handle.net/1822/35546

Zouros, N. (2005). Assessment, protection, and promotion of geomorphological and geological sites in the Aegean area, Greece. Géomorphologie: relief, processus, environnement, 11(3), 227-234. http://doi.org/10.4000/geomorphologie.398

Artigo recebido em/ Received on: 12/11/2019

Artigo aceite para publicação em/ Accepted for publication on: 11/12/2019 
Figueiró e Von Ahn / Physis Terrae, Vol. 1, n², 2019, 3-19

Página intencionalmente deixada em branco 